\title{
Water quality of the surfaces waters of the Barlinek Lake of the during stagnation time of 2008
}

\section{Ocena jakości wód powierzchniowych jeziora Barlineckiego w okresie stagnacji letniej w 2008 roku}

\author{
Piotr Daniszewski \\ Katedra Chemii i Ochrony Środowiska Wodnego \\ Wydział Biologii, Uniwersytet Szczeciński \\ ul. Felczaka 3C, 71-412 Szczecin, Poland \\ e-mail: daniszewski@univ.szczecin.pl
}

\begin{abstract}
To estimate differentiation of water chemistry in reservoirs of Barlinek Lake, of the during stagnation time of 2008. In arbitrary appointed times 19 physical and chemical indicators of water quality were determined to evaluate general status and water condition (temperature, $\mathrm{pH}$, concentration of dissolved oxygen and saturation by $\mathrm{O}_{2}$, solid residue, residue after ignition), trophy (concentrations of $\mathrm{NO}_{3}^{-}$, $\mathrm{NO}_{2}^{-}, \mathrm{NH}_{4}^{+}, \mathrm{PO}_{4}{ }^{3-}$ dissolved., $\mathrm{P}_{\text {tot. }}$ ), and mineralization (specyfic electrolytic conductivity, total hardness and separately concentrations of $\mathrm{Ca}^{2+}, \mathrm{Mg}^{2+}$ and $\mathrm{Cl}^{-}, \mathrm{SO}_{4}{ }^{2-}$, total concentrations of $\mathrm{Fe}$ and $\mathrm{Mn}$ ).
\end{abstract}

Keywords

Lakes; natural water quality; phosphorus; nitrogen; Barlinek Lake; summer stagnation

\section{STRESZCENIE}

Celem niniejszej pracy było prześledzenie w okresie stagnacji letniej w 2008 roku poziomu oraz dynamiki zmian w wodach jeziora Barlineckiego parametrów ogólnych, zasobności wód w substancje biogenne a także poziomu wskaźników mineralizacji. W pracy oznaczano wskaźniki ogólne wody:

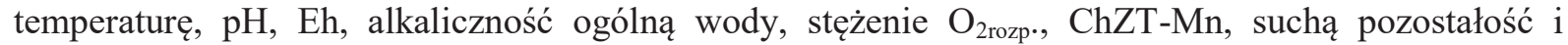
pozostałość po prażeniu. Spośród wskaźników charakteryzujących trofię oznaczono: stężenia $\mathrm{NO}_{3}{ }^{-}$, $\mathrm{NO}_{2}^{-}, \mathrm{NH}_{4}^{+}, \mathrm{PO}_{4}^{3-}$ roz. $\mathrm{P}_{\mathrm{og}}$ oraz wskaźniki charakteryzujące mineralizację wód: twardość ogólną, stężenie $\mathrm{Ca}^{2+}, \mathrm{Mg}^{2+}, \mathrm{Cl}^{-}, \mathrm{SO}_{4}{ }^{2-}$, ogólne stężenie $\mathrm{Fe}$ i $\mathrm{Mn}$. Stopień natlenienia wód obliczano na podstawie tablic nasycenia czystej wody tlenem atmosferycznym. Wszystkie oznaczenia i obliczenia wykonywano według metod zalecanych przez Polskie Normy, stosując procedury analityczne opisane m.in. przez Dojlido 1995; Elbanowska H. i in. 1999; Hermanowicza i in. 1999.

Słowa kluczowe

jeziora, jakość wód, fosfor, azot, jezioro Barlineckie, stagnacja letnia 


\section{WPROWADZENIE}

Stan jakości wód w zbiornikach wodnych w głównej mierze zależy od zawartości związków biogenicznych i ich dostępności biologicznej [Barik S.K. i in. 2001; Koc A., Skwierawski A, 2004]. Postępujące uprzemysłowienie, rozwój rolnictwa na obszarach zlewni, rozwój turystyki wpływają na nadmierne obciążenie akwenów wodnych przede wszystkim związkami biogennymi, które mają istotny wpływ na jakość wód (Kajak Z. 1979; Kalff 2001; Kubiak J. 1997, 2000; Lampert W., Sommer U., 2001; Vollenweider R. A., 1989).

Jak wynika $\mathrm{z}$ dokonanego przeglądu literatury, jak dotąd nie prowadzono szczegółowych badań dotyczących stanu jakości wód jeziora Barlineckiego.

Celem badań w niniejszej pracy było prześledzenie w okresie lata (lipiec i sierpień) 2008 roku poziomu oraz dynamiki zmian w wodach jeziora Barlineckiego parametrów ogólnych, zasobności wód w substancje biogenne a także poziomu wskaźników mineralizacji [1-18].

\section{CZEŚŚ DOŚWIADCZALNA}

Badania przeprowadzono na jeziorze Barlineckim, które zajmuje powierzchnię 259,1 ha, posiada trzy dopływy i jeden odpływ. Otoczone jest morenowymi wzgórzami, w większości porośniętymi buczynami. Fragment brzegu zachodniego badanego jeziora przylega do łąk połączonych z polami uprawnymi. Północna i północno-wschodnia część jeziora graniczy z zabudowaniami miasta Barlinek (Marcinkiewicz W. 1963). Podstawowe dane morfometryczno-zlewniowe badanego jeziora przedstawiono w tabeli $\mathrm{nr} 1$.

Współrzędne geograficzne stanowisk pomiarowych rozmieszczonych na jeziorze Barlineckim:

Stanowisko nr 1 - N: 52 58' 19,31" E: $15^{\circ} 11^{\prime} 45,69^{\prime \prime}$

Stanowisko nr 2 - N: $52^{\circ} 58^{\prime} 45,74^{\prime \prime}$ E: $15^{\circ} 12^{\prime} 27,14^{\prime \prime}$

Stanowisko nr 3 - N: $52^{\circ} 59^{\prime} 05,08^{\prime \prime}$ E: $15^{\circ} 13^{\prime} 07,81^{\prime \prime}$

Stanowisko nr 4 - N: $52^{\circ} 59^{\prime} 27,55^{\prime \prime}$ E: $15^{\circ} 13^{\prime} 12,20^{\prime \prime}$

Tabela 1. Dane morfometryczno-zlewniowe jeziora Barlineckiego

\begin{tabular}{|c|c|c|c|c|c|c|c|}
\hline \multirow[t]{3}{*}{ Lp. } & \multirow[t]{3}{*}{$\begin{array}{l}\text { Nazwa } \\
\text { jeziora } \\
\text { Lake } \\
\text { name }\end{array}$} & $\begin{array}{c}\text { Szerokość } \\
\text { geograficzna } \\
\text { Latitude }\end{array}$ & $\begin{array}{c}\text { Długość } \\
\text { geograficzna } \\
\text { Longitude }\end{array}$ & $\begin{array}{c}\text { Wysokość } \\
\text { n.p.m. } \\
\text { Height } \\
\text { above see } \\
\text { level }\end{array}$ & $\begin{array}{c}\text { Głębokość } \\
\text { maksymalna } \\
\text { Maximal } \\
\text { depth }\end{array}$ & $\begin{array}{l}\text { Głębokość } \\
\text { średnia } \\
\text { Average } \\
\text { depth }\end{array}$ & $\begin{array}{c}\text { Powierzchnia } \\
\text { zw. wody } \\
\text { Water } \\
\text { surface area }\end{array}$ \\
\hline & & $\mathrm{N}$ & $\mathrm{E}$ & $\mathrm{m}$ & $\mathrm{m}$ & $\mathrm{M}$ & ha \\
\hline & & $52^{\circ} 58,9^{\prime}$ & $15^{\circ} 12,9^{\prime}$ & 57,0 & 18,0 & 7,1 & 259,1 \\
\hline \multirow[t]{3}{*}{1.} & \multirow[t]{3}{*}{$\begin{array}{l}\text { Barlineckie } \\
\text { (Barlińskie) }\end{array}$} & $\begin{array}{c}\text { Powierzchnia } \\
\text { wysp } \\
\text { Island area }\end{array}$ & $\begin{array}{l}\text { Objętość } \\
\text { Volume }\end{array}$ & $\begin{array}{c}\text { Długość } \\
\text { maksymal } \\
\text { na } \\
\text { Maximal } \\
\text { length }\end{array}$ & $\begin{array}{c}\text { Szerokość } \\
\text { maksymalna } \\
\text { Maximal } \\
\text { width }\end{array}$ & $\begin{array}{c}\text { Linia } \\
\text { brzegowa } \\
\text { misy } \\
\text { jeziora } \\
\text { Coastline } \\
\text { of lake's } \\
\text { basin } \\
\end{array}$ & $\begin{array}{c}\text { Linia } \\
\text { brzegowa } \\
\text { wysp } \\
\text { Islands } \\
\text { coastline }\end{array}$ \\
\hline & & ha & $10^{3} \mathrm{~m}^{3}$ & $\mathrm{~m}$ & $\mathrm{~m}$ & $\mathrm{M}$ & $\mathrm{m}$ \\
\hline & & 3,7 & 18579,8 & 3770 & 2150 & 10450 & 1550 \\
\hline
\end{tabular}


Ocenę jakości wód powierzchniowych jeziora Barlineckiego prowadzono określając wartości 19 wskaźników, które określają jakość wód, a są uznawane za podstawowe (Dojlido 1995; Elbanowska H., i in. 1999; Hermanowicz W., i in. 1999) przy ustalaniu statusu ogólnego, trofii i mineralizacji wód.

Próby wody do badań pobierano według PN/C-04632.03 z głębokości ok. 0,5 m poniżej lustra wody. W miejscu poboru prób oznaczano temperaturę, $\mathrm{pH}$, potencjał redoks (Eh) oraz alkaliczność ogólną wód. Pobrane próbki wody zostały utrwalane zgodnie z zaleceniami zawartymi w Polskiej Normie - PN/C-04632.04.

Pozostałe wskaźniki określające jakość wód zostały oznaczone w przeciągu 24 godzin od momentu pobrania prób.

Oznaczenie ilości rozpuszczonej materii organicznej podatnej na utlenienie określano jako ChZT-Mn zgodnie z PN/C-04578.02. Tlen rozpuszczony oznaczono metodą Winklera w modyfikacji azydkowej Alsterberga $z$ zastosowaniem PN/C-04545.03. Stopień natlenienia wód określono według tablic zamieszczonych w pracy Nemerowa (1985). W wyniku oznaczeń „suchej pozostałości” i „pozostałości po prażeniu” - według PN/C-04541, określono ilość substancji rozpuszczonych po wprowadzeniu poprawki na ubytek masy związanej z rozkładem wodorowęglanów oraz szacować ilość rozpuszczonej materii organicznej [Macioszczyk 1987].

W niniejszej pracy spośród wskaźników trofii wód oznaczono również stężenie $\mathrm{NH}_{4}{ }^{+}$ - zgodnie z PN/C-04576.01, $\mathrm{NO}_{2}^{-}$- zgodnie z PN/C-04576.06, $\mathrm{NO}_{3}^{-}$- zgodnie z PN/C04576.09, $\mathrm{PO}_{4}{ }^{3-}$ rozp - zgodnie z PN/C-04537.02 i $\mathrm{P}_{\text {og }}$ - zgodnie z PN/C-04537.09.

Ocenę wskaźników mineralizacji badanego zbiornika wodnego tj. ogólne wskaźniki mineralizacji oraz makroskładniki i wybrane mikroskładniki mineralizacyjne: przewodnictwo elektrolityczne właściwe oznaczano zgodnie z PN/C-04542, twardość ogólną - oznaczano zgodnie z PN/C-04554.02, stężenie wapnia i magnezu - oznaczano zgodnie z PN/C-04551.01 i PN/C-04562.01, stężenie chlorków - oznaczano zgodnie z PN/C-04617.02, siarczanów (VI) - oznaczano zgodnie z PN/C-04566.09, alkaliczność ogólną - oznaczano zgodnie z PN/C04540.03, stężenie $\mathrm{Fe}_{\mathrm{og}}$ - oznaczano zgodnie z PN/C-04586.03 i $\mathrm{Mn}_{\mathrm{og}}$ - oznaczano zgodnie z PN/C-04590.01.

Poszczególne wskaźników jakości wód oceniano według kryteriów zalecanych do oceniania śródlądowych wód powierzchniowych określonych w Rozporządzeniu Ministra Środowiska z dnia 11 lutego 2004 r. w sprawie klasyfikacji dla prezentowania stanu wód powierzchniowych i podziemnych, sposobu prowadzenia monitoringu oraz sposobu interpretacji wyników i prezentacji stanu tych wód.

W pracy przedstawiono 19 wskaźników określających jakość wód, wśród których 18 było zawartych w przytoczonym powyżej rozporządzeniu.

\section{DYSKUSJA WYNIKÓW}

Wyniki badań wybranych wskaźników wód jeziora Barlineckiego wraz z klasyfikacją wartości zmierzonych wskaźników wg kryteriów zawartych w Rozporządzeniu Ministra Środowiska z dnia 11 lutego 2004 r. przedstawiono w tabeli 2. 
Tabela 2. Wyniki badań jakości wód powierzchniowych jeziora Barlineckiego (wiosna, lato i jesień 2008) wraz z klasyfikacją wartości badanych wskaźników wg kryteriów Rozporządzenia Ministra Środowiska z dnia 11 lutego 2004 r.

\begin{tabular}{|c|c|c|c|}
\hline \multirow{2}{*}{$\begin{array}{l}\text { Lp. } \\
\text { No }\end{array}$} & \multirow{2}{*}{$\begin{array}{l}\text { Wskaźnik jakości wód (jednostki) } \\
\text { Water quality indices (units) }\end{array}$} & \multicolumn{2}{|c|}{$\begin{array}{c}\text { Jezioro Barlineckie } \\
\text { Barlineckie Lake }\end{array}$} \\
\hline & & 24.07.2008 & 20.08 .2008 \\
\hline 1 & 2 & 3 & 4 \\
\hline \multicolumn{4}{|c|}{ I. Parametry ogólne / General parameters } \\
\hline I.1 & Temperatura wody / Water temperature $\quad\left({ }^{\circ} \mathrm{C}\right)$ & $19,0(\mathrm{I})$ & $17,6(\mathrm{I})$ \\
\hline I. 2 & $\begin{array}{l}\text { (jedn. } \mathrm{pH}) \\
\text { (pH units) }\end{array}$ & 7,75 (I) & $7,81(\mathrm{I})$ \\
\hline I.3 & ChZT-Mn / COD-Mn & 9,3 (III) & 8,9 (III) \\
\hline I.4 & $\mathrm{BZT}_{5} / \mathrm{BOD}_{5}$ & 5,7 (III) & 5,1 (III) \\
\hline I.5 & $\mathrm{O}_{2 \text { rozp. }} / \mathrm{O}_{2 \text { diss. }}$ & $9,7(\mathrm{I})$ & $8,8(\mathrm{I})$ \\
\hline I.6 & Natlenienie wód ${ }^{1)} /$ Saturation with $\mathrm{O}_{2}{ }^{1)}$ & 112,4 & 103,2 \\
\hline \multicolumn{4}{|c|}{ II. Zasobność wód w substancje biogenne/ Biogenics substances content } \\
\hline II.1 & $\left(\mathrm{mgN} \cdot \mathrm{dm}^{-3}\right)$ & $0,28(\mathrm{I})$ & $0,25(\mathrm{I})$ \\
\hline III.2 & $\left(\mathrm{mgN} \cdot \mathrm{dm}^{-3}\right)$ & 0,038 (II) & 0,036 (II) \\
\hline II. 3 & $\left(\mathrm{mgN} \cdot \mathrm{dm}^{-3}\right)$ & 0,57 (II) & 0,53 (II) \\
\hline II.4 & $\mathrm{PO}_{4}^{3-}$ rozp. $/ \mathrm{PO}_{4}^{3-}$ diss. & 0,74 (IV) & 0,67 (III) \\
\hline III.5 & $\left(\mathrm{mg} \mathrm{P}^{\prime} \mathrm{dm}^{-3}\right)$ & 0,23 (II) & 0,27 (II) \\
\hline \multicolumn{4}{|c|}{ III. Wskaźniki mineralizacji/ Mineralization indices } \\
\hline III.1 & $\begin{array}{l}\text { Przewodnictwo elektryczne właściwe/ } \\
\text { Specyfic electroconductivity }\end{array}$ & 480 (I) & 420 (I) \\
\hline III.2 & $\left(\mathrm{mg} \mathrm{Ca} \cdot \mathrm{dm}^{-3}\right)$ & 59 (II) & 55 (II) \\
\hline IIII.3 & $\left(\mathrm{mg} \mathrm{Mg} \mathrm{dm}^{-3}\right)$ & $8(\mathrm{I})$ & $8(\mathrm{I})$ \\
\hline III.4 & $\left(\mathrm{mg} \mathrm{Cl} \cdot \mathrm{dm}^{-3}\right)$ & $32(\mathrm{I})$ & $41(\mathrm{I})$ \\
\hline III. 5 & $\left(\mathrm{mg} \mathrm{SO}_{4} \mathrm{dm}^{-3}\right)$ & $76(\mathrm{I})$ & $87(\mathrm{I})$ \\
\hline III.6 & Zasadowość ogólna / Total alkalinity $\left(\mathrm{mgCaCO}_{3} \mathrm{dm}^{-3}\right)$ & 147 (II) & 157 (II) \\
\hline III.7 & $\mathrm{Fe}_{\text {og. }} / \mathrm{Fe}_{\text {tot. }} \quad\left(\mathrm{mg} \mathrm{Fe} \mathrm{dm}^{-3}\right)$ & 0,18 (II) & 0,24 (II) \\
\hline III.8 & $\left(\mathrm{mg} \mathrm{Mndm}^{-3}\right)$ & 0,07 (II) & 0,08 (II) \\
\hline
\end{tabular}

Objaśnienia/ explanation:

1) Wskaźnik jakości wód nie klasyfikowany w Rozporządzeniu Ministra Środowiska z dnia 11 lutego $2004 \mathrm{r}$.

${ }^{1)}$ Water quality indices not classificated by Rozporządzenie (2004).

Wody jeziora Barlineckiego w okresie prowadzonych badań posiadały wartości $\mathrm{pH}$ zbliżone do obojętnego tj. od 7,68 do 7,81 - zaliczane są do I klasa jakości wód.

Mierzone wartościami Eh wskazywały na to, iż mierzony potencjał redoks był kształtowany przez parę redoksową: $\mathrm{NO}_{3}{ }^{-} / \mathrm{NH}_{4}{ }^{+}$[Kölling M. 1986].

Natlenienie badanych wód w okresie lipca i sierpnia 2008 roku wahało się w granicach około $110 \%$.

Wysoki poziom natlenienia badanego zbiornika $\mathrm{w}$ badanym okresie był spowodowany rozwojem roślinności wodnej. W pozostałych porach roku tj. $\mathrm{w}$ okresie wiosny i jesieni wody były zdecydowanie niedotlenione - na co wskazują wyniki badań przeprowadzone przez autora $w$ innych porach roku [Daniszewski P. 2012].

W ekosystemach wodnych badanego jeziora znaczne wartości straty przy prażeniu oraz nieodpowiadające im wartości ChZT-Mn jak wynika z szacowań, jakie dokonano na podstawie oznaczeń „,suchej pozostałości” i ,pozostałości po prażeniu” wg [Macioszczyk A. 1987] oraz na podstawie wyników oznaczeń ChZT-Mn, którego wartości w okresie prowadzonych badań odpowiadały III klasie jakości wód. 
Przyczynę tego stanu należy upatrywać również w osadzie dennym badanego jeziora, który zasobny jest w materię organiczną.

Badane wody jeziora Barlineckiego zawierały zawsze stosunkowo mało mineralnych związków azotu - stężenia mineralnych form azotu odpowiadały zazwyczaj I i II klasie jakości wód.

Badane wody posiadały zmieniające się stężenia $\mathrm{PO}_{4}{ }^{3-}$ rozp $\mathrm{i} \mathrm{P}_{\mathrm{og}}-$ stężenia te odpowiadały wodom od II do IV klasy jakości. Wzrost stężeń związków fosforu w badanym jeziorze może świadczyć o spadku ilości tlenu w wodach naddennych i zmianami ich statusu redoks prowadzącymi do uwalniania związków fosforu skumulowanych w osadach dennych [Kajak Z. 1998].

Ekosystem jeziora Barlineckiego jest zasobny w związki fosforu, które stanowią obciążenie wewnętrzne tego ekosystemu. Przemawia za tym uwalnianie z osadów do toni wodnej obok związków fosforu, także manganu i żelaza do wartości odpowiadających II klasie jakości wód.

Wskaźniki mineralizacji wód badanego jeziora cechowały się ustabilizowanym stężeniem badanych makroskładników jonowych wody.

\section{WNIOSKI}

1. W okresie badawczym wody powierzchniowe Jeziora Barlineckiego z uwagi na wyniki oznaczeń ChZT-Mn były wodami III klasy jakości oceniając wg przepisów obowiązujących do oceny wód powierzchniowych w Polsce.

2. Badane wody były klasyfikowane do IV klasy jakości ze względu na wartości stężeń $\mathrm{PO}_{4}{ }^{3-}$.

3. Badane wody jeziora Barlineckiego były słabo zmineralizowanymi. Stężenia soli mineralnych $\mathrm{w}$ badanym jeziorze podlegały niedużym wahaniom $\mathrm{w}$ okresie stagnacji letniej.

4. Znaczne zmiany natlenienia wód badanego jeziora $\mathrm{w}$ odniesieniu do prowadzonych badań w okresie wiosny i lata 2008 roku [Daniszewski P. 2012], poczynając od stanów silnego przetlenienia w okresie letnim - spowodowane jest stosunkowo krótkotrwałym bujnym rozwojem roślinności wodnej - do stanów niedotlenienia w okresie przede wszystkim wiosny.

\section{LITERATURA}

[1] Barik S.K., Purushothaman C.S., Mohanty A.N.. Aquaculture Research, 32 (2001) 819-832

[2] Daniszewski P. International Letters of Chemistry, Physics and Astronomy, 1 (2012) 6-12

[3] Dojlido J.R. Chemia wód powierzchniowych. Wydawnictwo Ekonomia i Środowisko. 1995

[4] Elbanowska H., Zerbe J., Siepak J. Fizyczno-chemiczne badania wód. Wydawnictwo Naukowe PWN, 1999, s. 232

[5] Hermanowicz W., Dojlido J., Dożańska W., Koziorowski B., Zerbe J., Fizyczno-chemiczne badanie wody i ścieków. Arkady, Warszawa 1999 
[6] Kajak Z.. Hydrobiologia-Limnologia. Ekosystemy wód śródlądowych, PWN, Warszawa 1998, s. 355.

[7] Kentzer A.. Fosfor i jego biologicznie dostępne frakcje w jeziorach o równej trofii, Wydawnictwo UMK, Torun, 2001, s. 111.

[8] Koc A., Skwierawski A,. Fosfor w wodach obszarów rolniczych, Prace Naukowe Akademii Ekonomicznej we Wrocławiu, (2004), 168, 1017,

[9] Kölling M.. Vergleich verschiedener Methoden zur Bestimmung des Redoxpotentials natürlicher Wässer. Meyniana. 38 (1986) $1 \div 19$.

[10] Kubiak J., Nedzarek A., Tórz A., Materiały 17 Zajazdu Hydrobiologów Polskich, 8-11 września. Poznań 1997, s. 40-41.

[11] Kubiak J., Wechterowicz Z., Tadajewski A., Materiały 18. Zjazdu Hydrobiologów Polskich, 4-8 września. Białystok 2000, s. 141-142.

[12] Lampert W., Sommer U.. Ekologia wód śródlądowych. Wyd. Nauk. PWN, Warszawa 2001, s. 415.

[13] Macioszczyk A.. Hydrogeochemia. Wyd. Geologiczne, Warszawa 1987, s. 475.

[14] Marcinkiewicz W., Barlineckie Jezioro. Wyd. Instytut Rybactwa Śródlądowego, Olsztyn 1963

[15] Nemerow N.L., Stream, lake, estuary, and ocean pollution, Van Nostrand Reinhold Company, New York. 1985

[16] Rozporządzenie Ministra Środowiska z dnia 11 lutego 2004 r. (Dz. U. Nr 32, poz. 284).

[17] Siuda W.. Post. Mikrobiol. 40 (2) (2001) 187-217.

[18] Vollenweider R. A., Symp. Biol. Hung., 38 (1989) 19-41.

\section{Polskie Normy}

PN/C-04537.02. Oznaczanie rozpuszczonych ortofosforanów kolorymetryczną metodą molibdenianową z chlorkiem cynawym jako reduktorem.

PN/C-04537.09. Woda i ścieki. Badania zawartości związków fosforu. Oznaczenie fosforu ogólnego.

PN/C-04540.03. Badania wartości pH, kwasowości i zasadowości. Oznaczanie kwasowości i zasadowości mineralnej i ogólnej metodą miareczkowania wobec wskaźników.

PN/C-04541. Oznaczanie suchej pozostałości, pozostałości po prażeniu, straty przy prażeniu oraz substancji rozpuszczonych, substancji mineralnych i substancji rozpuszczonych lotnych.

PN/C-04542. Oznaczanie przewodności elektrolitycznej właściwej.

PN/C-04545.03. Oznaczanie rozpuszczonego tlenu metodą Winklera w modyfikacji azydkowej.

PN/C-04551.01. Oznaczanie wapnia (twardości wapniowej) metodą wersenianową.

PN/C-04554.02. Oznaczanie twardości ogólnej powyżej 0,357 mval $/ \mathrm{dm}^{3}$ metodą wersenianową. 
PN/C-04562.01. Oznaczanie magnezu metodą wersenianową.

PN/C-04566.09. Badania zawartości siarki i jej związków. Oznaczanie siarczanów metodą wagową.

PN/C-04576.01. Badania zawartości związków azotu. Oznaczanie azotu w postaci amoniaku i jonów amonowych.

PN/C-04576.06. Oznaczanie azotu azotynowego metodą kalorymetryczną $\mathrm{z}$ kwasem sulfanilowym i 1-naftyloaminą.

PN/C-04576.09. Oznaczanie azotu azotanowego metodą kalorymetryczną z p-fluorofenolem.

PN/C-04578.02. Badania zapotrzebowania tlenu i zawartości węgla organicznego. Oznaczanie chemicznego zapotrzebowania tlenu (ChZT) metodą nadmanganianową.

PN/C-04586.03. Oznaczanie żelaza ogólnego i rozpuszczonego w zakresie $0,02-10 \mathrm{mg} / \mathrm{dm}^{3}$ metodą kolorymetryczną z 1,10-fenantroliną lub 2,2'-dwupirydylem.

PN/C-04590.01. Oznaczanie manganu metodą kolorymetryczną nadmanganianową.

PN/C-04617.02. Oznaczanie chlorków w wodzie i ściekach metodą argentometrycznego miareczkowania.

PN/C-04632.03. Ogólne zasady pobierania próbek do badań fizycznych, chemicznych i biologicznych. Technika pobierania próbek.

PN/C-04632.04. Ogólne zasady pobierania próbek do badań fizycznych, chemicznych i biologicznych. Utrwalanie i przechowywanie próbek.

PN/C-06504. Przygotowanie roztworów buforowych. 